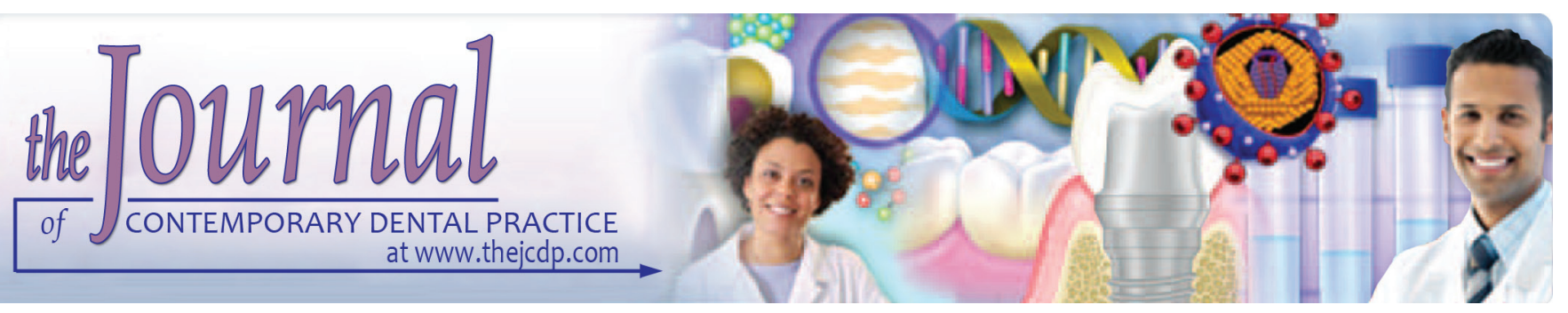

\title{
A Novel Mobile App for Oral Cancer Awareness amongst General Population: Development, Implementation, and Evaluation
}

\author{
${ }^{1}$ Saee Deshpande, ${ }^{2}$ Usha Radke, ${ }^{3}$ Tapasya Karemore, ${ }^{4}$ Rohit Mohril, ${ }^{5}$ Sudhir Rawlani, ${ }^{6}$ Pranav Ingole
}

\begin{abstract}
Aim: To develop a mobile app for education and screening regarding oral cancer in the general population.

Materials and methods: A mobile app titled Prayaas-Oral Cancer Prevention, Treatment, and Rehabilitation was designed and developed to be installed on a basic mobile handset with or without internet. It was aimed for the common public, patients as well as healthcare providers. The contents included all information in the pictorial format as well as videos regarding oral cancer awareness, tobacco de-addiction, self-oral examination, various surgeries, and rehabilitation options. It was pilot tested in 50 factory workers of rural set-up. Participants' feedback was recorded using a selfreport questionnaire.
\end{abstract}

Results: Overall feedback was very positive, they found the app easy to operate, enhancing knowledge regarding oral cancer and they recommended this to be used for the general population.

Conclusions: Within limitations of this pilot study, it can be inferred that mobile technology can be successfully used to reach out to bottom of the pyramid population residing in

1,2Department of Prosthodontics, Vidya Shikshan Prasarak Mandals Dental College and Research Centre, Nagpur, Maharashtra, India

${ }^{3}$ Department of Oral Medicine and Radiology, Vidya Shikshan Prasarak Mandals Dental College and Research Centre, Nagpur, Maharashtra, India

${ }^{4}$ Department of Oral Pathology, Vidya Shikshan Prasarak Mandals Dental College and Research Centre, Nagpur, Maharashtra, India

${ }^{5}$ Department of Public Health Dentistry, Vidya Shikshan Prasarak Mandals Dental College and Research Centre, Nagpur, Maharashtra, India

${ }^{6}$ Department of Oral Surgery, Vidya Shikshan Prasarak Mandals Dental College and Research Centre, Nagpur, Maharashtra, India

Corresponding Author: Saee Deshpande, Department of Prosthodontics, Vidya Shikshan Prasarak Mandals Dental College and Research Centre, Nagpur, Maharashtra, India, Phone: +919823794366, e-mail: drsaeedeshpande@gmail.com inaccessible rural population for creating public health issues such as oral cancer.

Clinical significance: Oral cancer is preventable through risk factor intervention especially tobacco de-addiction. The selforal examination can be a very critical factor in early diagnosis of oral cancer. Access to care is a major issue in our country owing to low levels of education, lower income and exposure to risk factors such as tobacco. The fact that today there is widespread use of mobile technology by people belonging to all socioeconomic groups can be harnessed for this public health awareness initiative. This app can be used as a tool for patient education for prevention as well as early detection of oral cancer, both of which can be key to reduce oral cancer morbidity and mortality in India.

Keywords: Mobile app, Oral cancer, Tobacco deaddiction.

How to cite this article: Deshpande S, Radke U, Karemore T, Mohril R, Rawlani S, Ingole P. A Novel Mobile App for Oral Cancer Awareness amongst General Population: Development, Implementation, and Evaluation. J Contemp Dent Pract 2019;20(2):190-196.

Source of support: Nil

Conflict of interest: None

\section{BACKGROUND}

India contributes up to $7.8 \%$ of global cancer burden and oral cancer is 3rd most common cancer in India. ${ }^{1}$ Risk factors such as environmental carcinogens, alcohol, infectious agents, and tobacco use are prevalent in developing countries. The common public in these countries also has less access to health services and health education that would empower them to make decisions to protect and improve their health. Additionally, a high risk of oral cancer in the Indian subcontinent is related to the popularity of betel leaf, lime, areca nut, and sun-cured tobacco chewing. ${ }^{2,3}$

Screening for oral cancer is, therefore, a need of an hour in general population, aimed at early detection of precancerous lesions and conditions, invasive cancers with improved survival after treatment of initial stages of cancers. ${ }^{4}$ 
Today, the mobile revolution is offering an excellent way to provide healthcare support when and where people need it. Mobile health (mHealth), the branch of eHealth broadly defined as "the use of mobile computing and communication technologies in health care and public health" has been constantly expanding. Mobile applications cater to heterogeneous audiences such as doctors, nurses, patients, or even healthy people. ${ }^{5}$ There are now 2,000 apps for the iPhone related to health or medicine. ${ }^{6,7}$ Platforms available today include Android, Apple iOS, RIM BlackBerry, Symbian, and Windows (Windows Mobile 6.x and the emerging Windows Phone 7 platform). ${ }^{8}$ These apps relate to the prevention of cancer such as breast cancer, smoking cessation, daily health monitoring and other chronic diseases such as diabetes. ${ }^{5}$ However, the distribution of apps is not equal in all prevalent disease conditions. ${ }^{9}$ There is no evidence of an app related to oral health especially oral cancer prevention in the Indian context. Relatively few apps have been developed in the local language and tested in research studies to determine their efficacy. ${ }^{10}$ In this paper, we discuss the process of development and testing of a new app for preventing oral cancer through tobacco cessation, awareness regarding pre-cancerous lesions and conditions, self-oral examination, various modalities for oral cancer treatment and rehabilitation.

\section{AIM}

To develop a mobile app for education and screening regarding oral cancer in the general population in the local language and determine its efficacy in the general population.

\section{OBJECTIVES}

- To increase awareness regarding the ill effects of tobacco and other risk factors related to oral cancer and precancer

- To create better motivation amongst the population for tobacco de-addiction and self-oral examination

- To increase early diagnosis of oral cancer and precancer and thereby prevent oral cancer

- To reduce cancer mortality and morbidity

\section{METHODOLOGY}

Protocol for app development was as follows:11,12

- Initial analysis of requirements,

- Technology and strategic planning,

- Design and architecture (identifying a suitable design, architecture, and interface for the mobile app),

- Development and coding (keeping the design in mind),

- Testing and approval (on a live server to identify and fix any coding bugs),

- Peer validation

- Implementation (field/pilot testing)

\section{App design: (Fig 1)}

This app runs on both Android as well as basic handsets with or without internet.

- Title: Prayaas-Oral Cancer Prevention, Treatment, and Rehabilitation

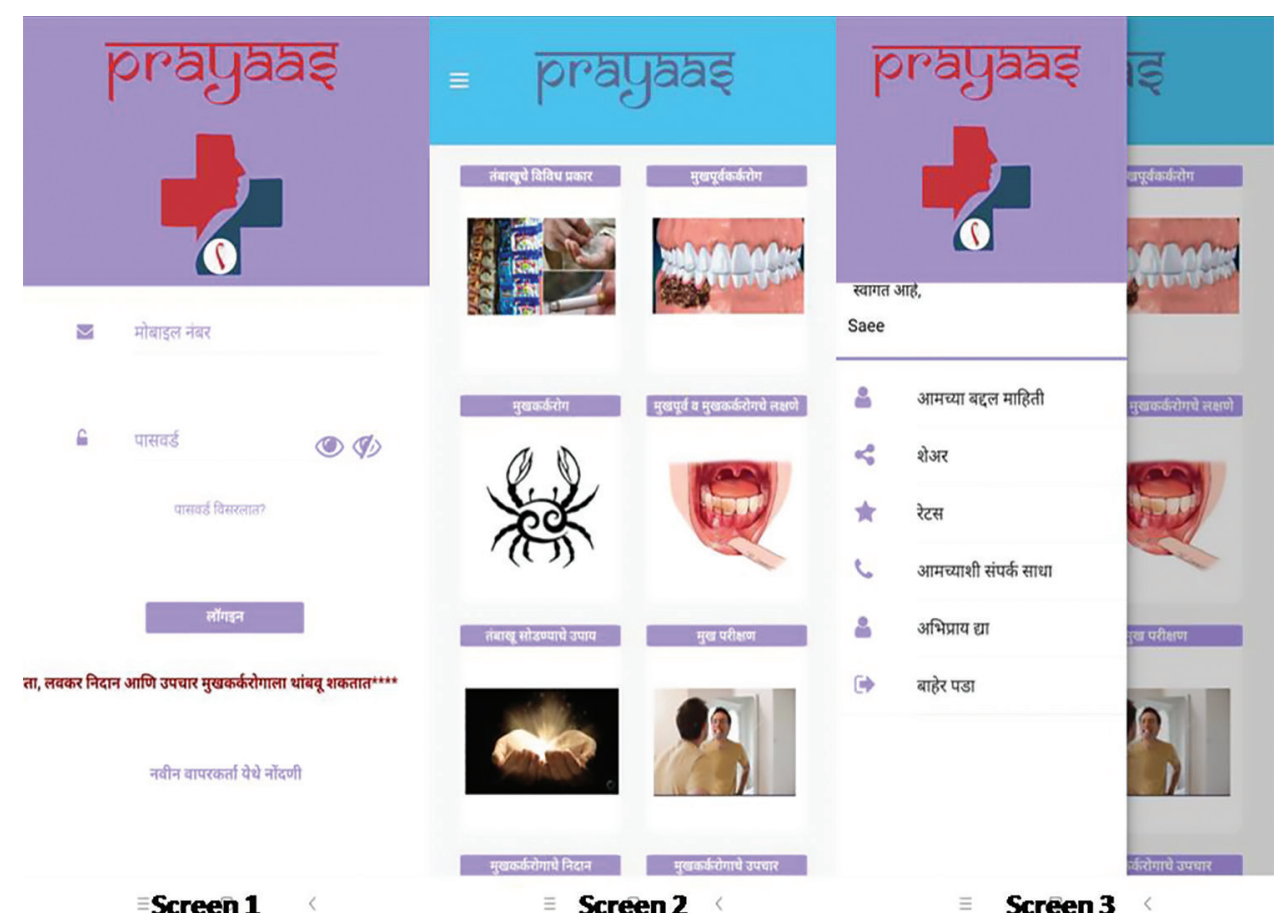

Fig. 1: App design 
A statement clearly declaring that the information on the app is not meant to replace the advice of a health professional is provided. A brief description of the app's mission, purpose, and intended audience is depicted. Another brief description of the organization behind the app, its mission, contact details, and its purpose is also necessary. Privacy policy, declaration of conflict of interest and source of funding was clearly mentioned.

\section{Home screen: Registration}

- Common public

- Patients

- Healthcare providers

\section{Subsequent Screen Content: In the form of text, pictures, and video}

- Tobacco-various forms and associated risks

- Tobacco-de-addiction strategies

- Precancerous and cancerous lesions and conditions

- Oral self-examination

- Common surgeries and resultant deformities Prosthodontic rehabilitation options

- Pre-radiation dental consultation

In addition to this, a facility to consult the expert via SMS was provided.

Healthcare providers can register themselves and access information as well as network and communicate with other registered care providers.

\section{Pilot testing}

The study is approved by the IRB of the institution. A pilot study was done on 50 employees working in Mahindra group of industries placed in the rural area of Nagpur. Informed consent was taken from all 50 employees. A detailed case history, oral examination and habit history was recorded. All recruited members had some form of tobacco habit. They attended the sensitizing session and downloaded the said app in their android mobile. They were suggested to use and try the app for the next four days and then feedback was obtained by self-reported pre-validated questionnaire.

\section{Data Analysis}

Participants' responses to Likert scale questions were assigned a numerical value ranging from one ("Strongly Disagree") to five ("Strongly Agree"). Using Microsoft Excel 2013 (Microsoft Corp., USA), we calculated mean response values for each question, and performed one-way T-tests to determine if the mean value of all responses to a question was significantly different from three-the value corresponding to "Neither Agree Nor Disagree." Free text responses to questions about course strengths and improvement needs were analyzed using the comparative source method. Two co-authors independently identified themes in participants' responses, then iteratively compared and refined their theme lists until they agreed on a common set of themes. Next, the evaluators independently quantified the number of distinct references to each theme in the responses. They repeatedly compared and revised their reference lists until they agreed on the number of references to each theme.

\section{RESULTS}

Mean age of participants was $41 \pm 12$ years. 37 males and 13 females participated in this study. They were all school educated with an average monthly income of Rs 20,000.

Feedback is summarized in Tables 1 and 2 and Graphs 1 to 6 .

Ninety percent of them agreed to the fact that it is important to know about tobacco and its effect on oral health. Eighty-eight percent of participants agreed that mobile technology can be successfully used as an adjunct to dental visit in oral cancer prevention. Eighty-eight percent of the participants found the app to be easy to use and ninety-eight percent felt that it increased their

Table 1: Results of feedback (in \%)

\begin{tabular}{|c|c|c|c|c|c|}
\hline Question & Strongly disagree & Disagree & Cannot say & Agree & Strongly agree \\
\hline $\begin{array}{l}\text { 1. I think it is important to know about tobacco and its } \\
\text { ill effects on oral health }\end{array}$ & 2 & 2 & 6 & 76 & 14 \\
\hline $\begin{array}{l}\text { 2. Technology (use of mobile phones) can be } \\
\text { effectively employed as an adjunct to actual dental } \\
\text { visit in spreading awareness regarding tobacco } \\
\text { deaddiction and oral cancer }\end{array}$ & 0 & 2 & 10 & 16 & 72 \\
\hline 3(i) App is easy to operate & 0 & 0 & 12 & 14 & 74 \\
\hline $\begin{array}{l}\text { 3(ii) I felt that app enhanced my knowledge about } \\
\text { tobacco deaddiction and oral cancer }\end{array}$ & 0 & 0 & 2 & 62 & 36 \\
\hline $\begin{array}{l}\text { 3(iii) This App could be useful to create awareness } \\
\text { among the public about oral cancer }\end{array}$ & 2 & 2 & 14 & 42 & 42 \\
\hline $\begin{array}{l}\text { 3(iv) By using this app I learnt about self oral } \\
\text { examination effectively }\end{array}$ & 2 & 2 & 16 & 22 & 58 \\
\hline
\end{tabular}


knowledge regarding tobacco deaddiction and self-oral examination for oral cancer prevention.

After analysis of the open-ended questions following themes emerged:
- The best thing about the app- 'local language, easy to understand, use of pictures and video'

- Things that can be improved-'live video calling facility, online reminders for de-addiction'.

Table 2: Statistical analysis of participants' responses

\begin{tabular}{|c|c|c|c|}
\hline Question & $\begin{array}{l}\text { Mean likert scale } \\
\text { response }\end{array}$ & $p$ value* & $\begin{array}{l}\text { Percent who strongly or somewhat } \\
\text { agree with statement }\end{array}$ \\
\hline $\begin{array}{l}\text { 1. I think it is important to know about tobacco and its } \\
\text { ill effects on oral health }\end{array}$ & 4.80 & $<0.0001$ & 90 \\
\hline $\begin{array}{l}\text { 2. Technology (use of mobile phones) can be } \\
\text { effectively employed as an adjunct to actual dental } \\
\text { visit in spreading awareness regarding tobacco } \\
\text { deaddiction and oral cancer }\end{array}$ & 4.85 & $<0.0001$ & 88 \\
\hline 3(i) App is easy to operate & 4.85 & 0 & 12 \\
\hline $\begin{array}{l}\text { 3(ii) I felt that app enhanced my knowledge about } \\
\text { tobacco deaddiction and oral cancer }\end{array}$ & 4.95 & $<0.0001$ & 98 \\
\hline $\begin{array}{l}\text { 3(iii) This App could be useful to create awareness } \\
\text { among the public about oral cancer }\end{array}$ & 4.76 & $<0.0001$ & 84 \\
\hline $\begin{array}{l}\text { 3(iv) By using this app I learnt about self oral } \\
\text { examination effectively }\end{array}$ & 4.75 & $<0.0001$ & 80 \\
\hline
\end{tabular}

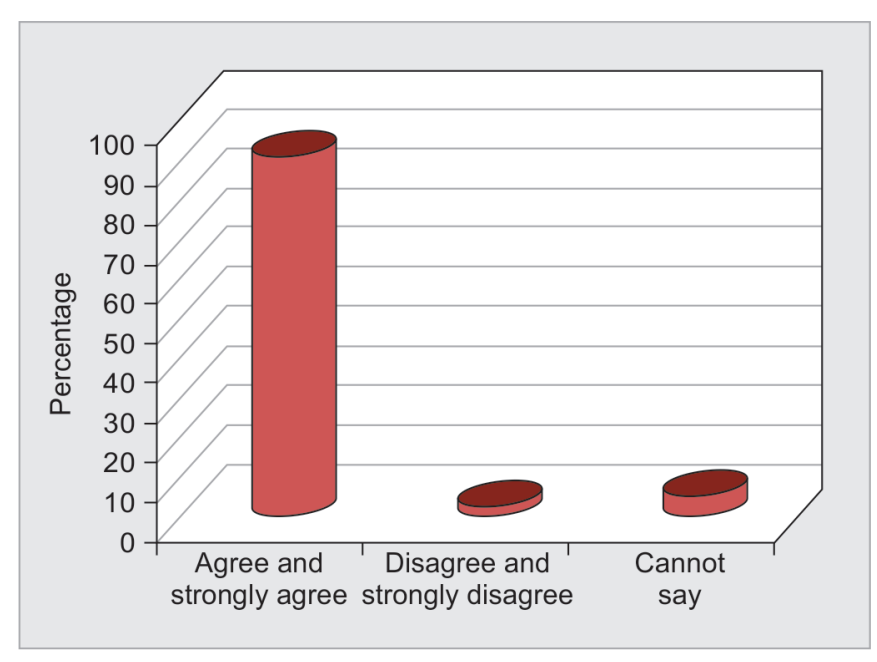

Graph 1: I think it is important to know about tobacco and its ill effects on oral health

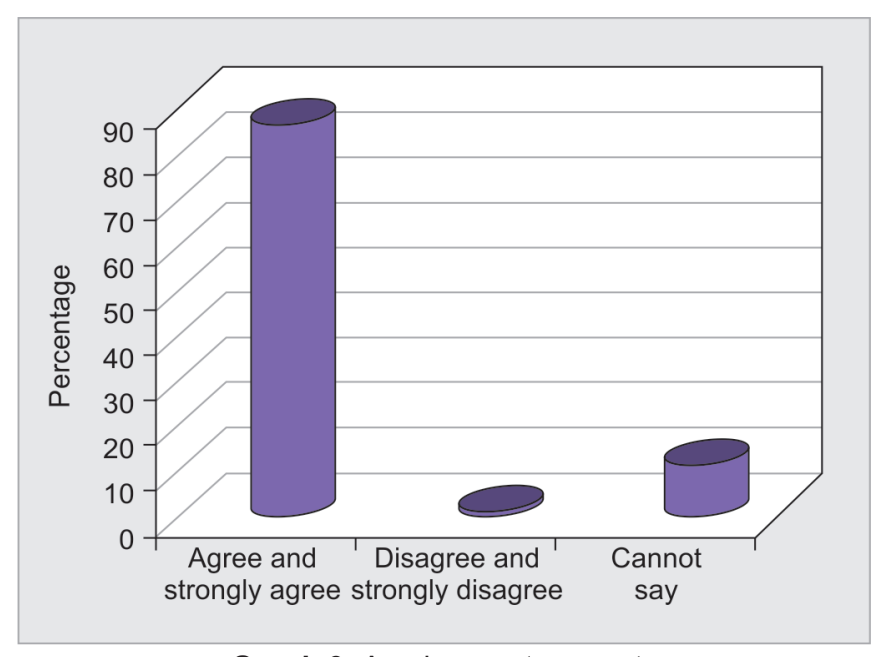

Graph 3: App is easy to operate

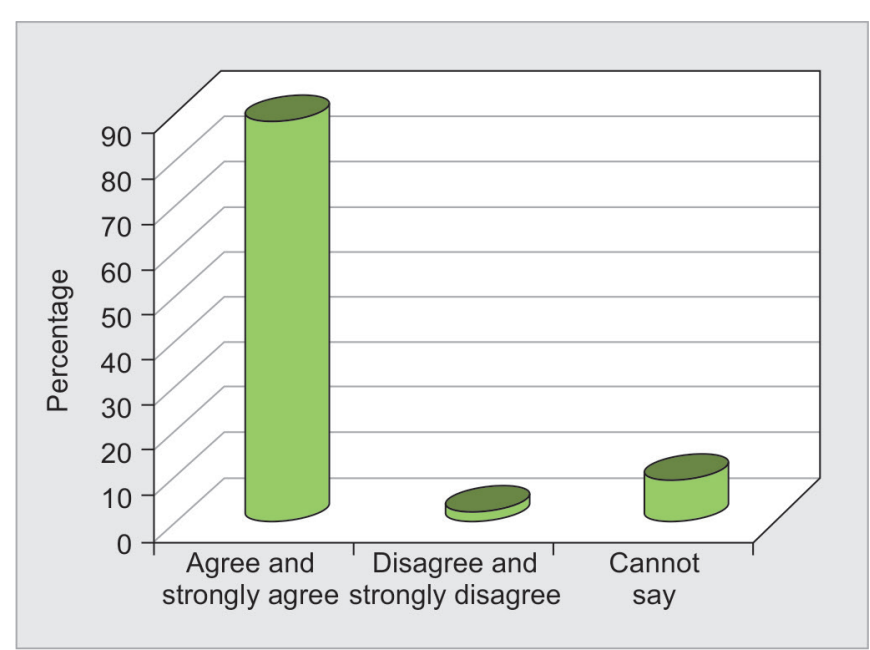

Graph 2: Technology (use mobile phones) can be effective as an adjunct to actual dental visit in spreading awareness regarding tobacco de-addiction and oral cancer

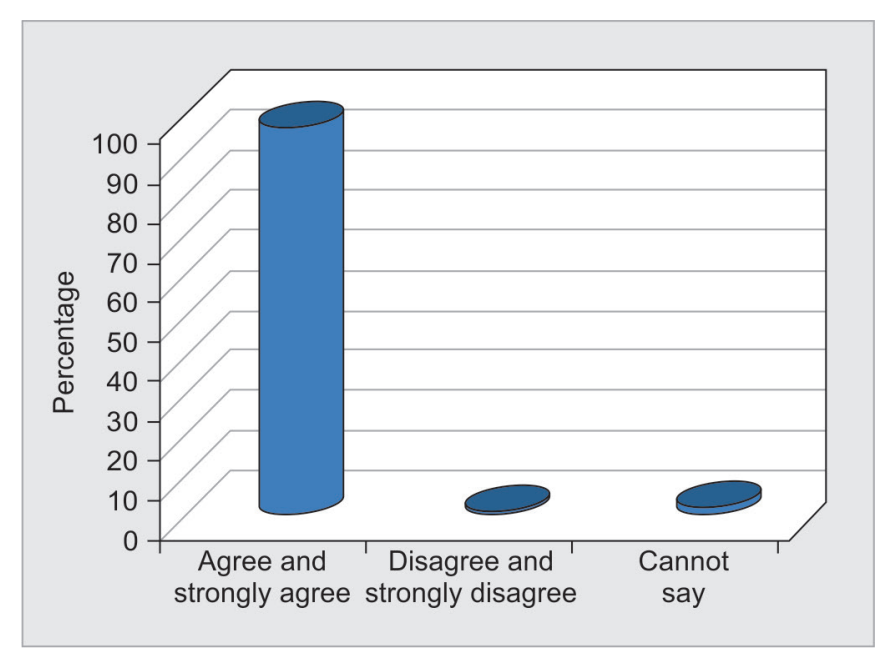

Graph 4: App enhanced my knowledge about tobacco de-addiction and oral cancer 


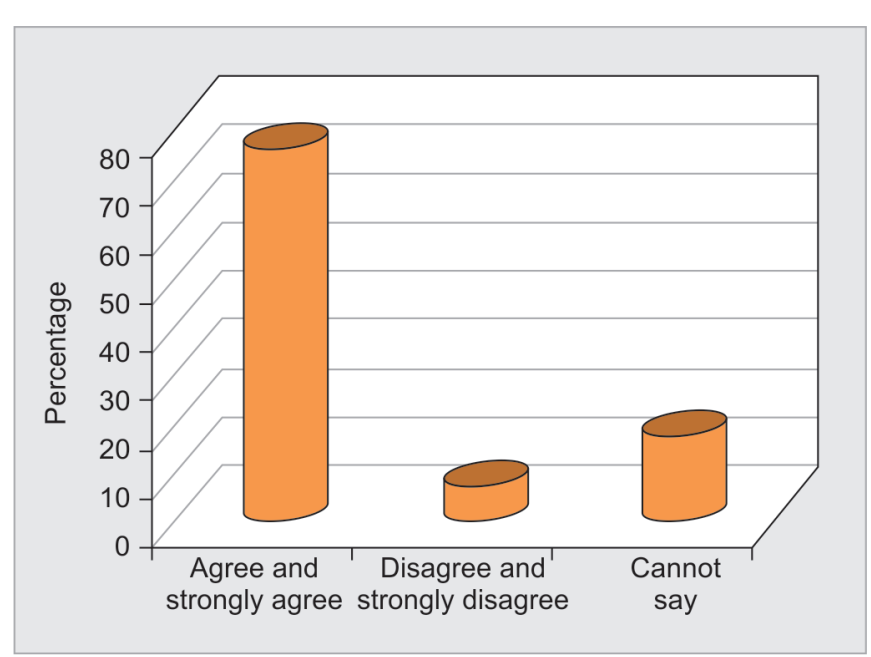

Graph 5: App could be useful to create awareness among the public about oral health

\section{DISCUSSION}

Oral cancer in India has the highest prevalence rate in the world (19/100000 population). Tobacco use is associated with $95 \%$ of cases. There are high morbidity and mortality associated with oral cancer. The 5-year survival rate is $75 \%$ for local lesions but only $17 \%$ for those with distant metastasis. ${ }^{2}$ Therefore early diagnosis is the key. Owing to the ease of access for examination and early pre-cancerous lesion or condition as a precursor, it is preventable to a great extent. As oral cancer is diagnosed at later stages, cost of treatment and its associated morbidity increases.

Tobacco deaddiction plays a pivotal role in cancer prevention. Various deaddiction strategies are helpful for getting rid of deadly habits of chewing/ smoking tobacco and other related products. The self-oral examination is also another way to monitor oral health and progress of precancerous lesions. It is very easy to perform and incurs no cost. Additionally, there is very little awareness about various maxillofacial deformities as a result of cancer surgery and various ways for rehabilitation. People also do not know various team members involved in oral cancer treatment and reconstruction which includes social workers as well.

Sankaranarayanan ${ }^{13}$ has discussed facts about oral cancer in India stating that only $10-15 \%$ of cases present in localized stages. The poor survival revealed by existing studies is mainly due to the overwhelming proportion of advanced cases. They highlighted the excellent opportunity for more research and efforts in prevention and control of oral cancer in India.

There has been gradual digitization of health and medical information since the advent of the Internet and the emergence of health and medical apps as one of the latest developments. Technology can come to the rescue in such situations where public health awareness has to be created at grass root levels. Today, with the advent of

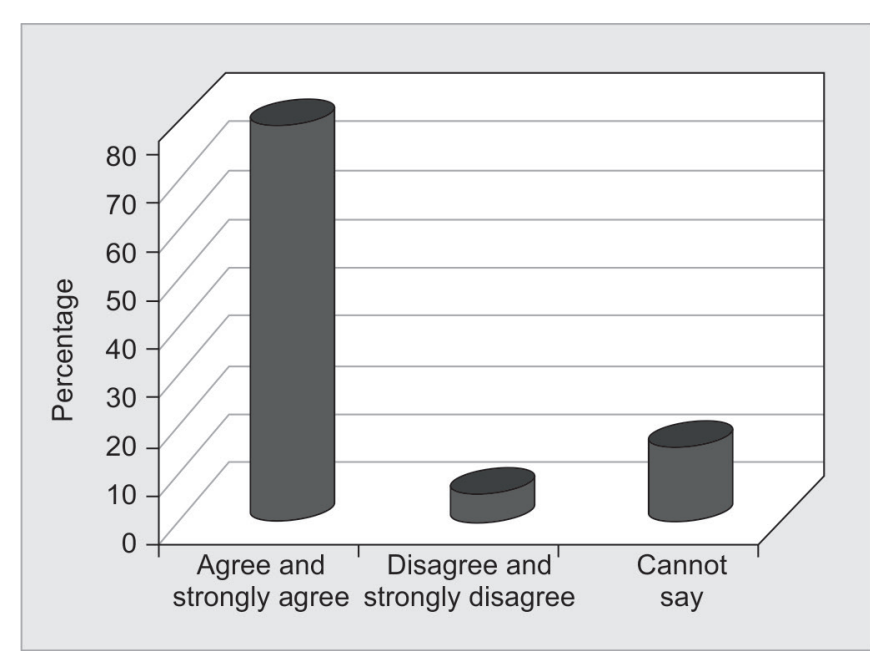

Graph 6: Buy using this app I learnt about self-oral examination effectively

cheaper handsets and service providers' mobile use has skyrocketed and this fact can be leveraged to disseminate important health information. ${ }^{14}$ Smartphones can play a very important role in patient education, disease selfmanagement, and remote monitoring of patients. ${ }^{15}$

Coughlin et al. ${ }^{10}$ reviewed the current status and future challenges of mobile phone apps for preventing cancer through educational and behavioral interventions. Smoking cessation app was found to be effective since a sizeable percentage of smokers reported being abstinent at 12 weeks. The breast cancer e-support program ${ }^{16}$ was helpful in enhancing knowledge, improving confidence level, and promoting emotional well-being during cancer chemotherapy especially from the tailored advice from experts. These studies report that apps were positively received by patients and the general public and recommended as a low cost, promising tool to reach out to the common public. Lee et al. ${ }^{17}$ developed and tested a 7-day mobile phone text message-based cervical cancer screening (m Screening) intervention designed to promote the receipt of Pap tests by young Korean American women. It was well received by participants and increased both knowledge and receipt of cervical cancer screening.

The present innovation employs mobile phone either with or without internet and on android or iOS-based devices. The basic objective is to impart basic information for oral cancer prevention, disability limitation, and rehabilitation to the general population. The app development involved a team for deciding its content and structure consisting of technical persons and subject experts from different dental specialties viz., Oral medicine, oral pathology, public health dentistry, and maxillofacial prosthodontics.

On technical front care was taken to cater to a wide variety of screen sizes, hardware specifications, and configurations of mobile devices, as well as the need to run on a battery. Every effort was made to have an 
understandable and user-friendly interface, including both hardware and software components. A framework to assess risk and promote safer use was followed to assess and to minimize the likely risks posed by a specific app in a specific context. ${ }^{10}$ Clear and comprehensive communication of risks related to tobacco consumption in various forms on oral health is depicted in a pictorial way in the local language in a way which is easy to understand. Common behavioral change techniques were included for tobacco de-addiction viz., providing feedback, goal-setting, self-monitoring, and providing expert guidance through an interactive interface. Selforal examination video is included for self-monitoring and early detection.

Various forms of oral cancer including signs and symptoms, their treatment, and rehabilitation part is also a part of this app. Apart from patients, this app is useful for healthcare providers and social workers for creating a professional network as well as public awareness.

As this is a pilot phase, we selected literate participants well versed with the use of a mobile app for the pilot study. Also, participants had some form of tobacco habit which was recorded in case history and habit history.

It was well received by the participants in our pilot testing (Graphs 1 to 4). Majority of them agreed to the fact that it is important to know about tobacco and its effect on oral health, to the fact that mobile technology can be successfully used as an adjunct to dental visit in oral cancer prevention. Most of the participants found the app to be easy to use and increased their knowledge regarding tobacco deaddiction and self-oral examination for oral cancer prevention. the use of local language, pictures and videos was found to be the best thing reported by all participants. Forty percent of participants mentioned that they wish to have an online follow up with experts regarding queries in the form of video calling. We are trying to add this feature in the updated version of the app.

The results are in accordance with a few similar interventions investigating utility and perceptions about harnessing mobile technology for cancer prevention and support. Since this is our pilot study, larger sample size and multicentre testing in diverse population groups are amongst the few inherent limitations. The quit tobacco feature of the app needs long term to follow-up for its utility. Also, the usability of the app in illiterate people from poor socioeconomic background needs to be evaluated.

\section{CONCLUSION}

Within limitations of this pilot study, it can be concluded that the continuous and pervasive social connectivity by using mobile phones holds a lot of potential in particular for use in healthcare education related to oral cancer and tobacco de-addiction. This app has been well received by its end users in this pilot study.

\section{CLINICAL SIGNIFICANCE}

The present mobile app can be effectively used as an adjunct to a clinical dental checkup to increase awareness about tobacco deaddiction and self-oral examination to prevent oral cancer in the general population.

\section{REFERENCES}

1. Petersen PE. Oral cancer prevention and control-The approach of the World Health Organization. Oral oncology. 2009 May 31;45(4):454-460.

2. Saranath D, Khanna A. Current status of cancer burden: global and Indian scenario. Biomed Res J. 2014;1(1):1-5.

3. Sankaranarayanan R. Oral cancer in India: An epidemiologic and clinical review 1990;69(3):325-330.

4. Nassem Shah. Oral and dental diseases: Causes, prevention and treatment strategies National commission on macroeconomics and health, Govt of India. 2005:275-298.

5. Fiordelli M, Diviani N, Schulz PJ. Mapping mHealth research: a decade of evolution. Journal of medical Internet research. 2013 May;15(5).

6. Terry M. Medical apps for smartphones. Telemedicine and e-Health. 2010 Jan 1;16(1):17-23.

7. Boulos MN, Brewer AC, Karimkhani C, Buller DB, Dellavalle RP. Mobile medical and health apps: state of the art, concerns, regulatory control and certification. Online journal of public health informatics. 2014;5(3):229.

8. Boulos MN, Wheeler S, Tavares C, Jones R. How smartphones are changing the face of mobile and participatory healthcare: an overview, with example from eCAALYX. Biomedical engineering online. 2011 Dec;10(1):24.

9. Martínez-Pérez B, De La Torre-Díez I, López-Coronado M. Mobile health applications for the most prevalent conditions by the World Health Organization: review and analysis. Journal of medical Internet research. 2013 Jun;15(6):e120.

10. Coughlin S, Thind H, Liu B, Champagne N, Jacobs M, Massey RI. Mobile phone apps for preventing cancer through educational and behavioral interventions: state of the art and remaining challenges. JMIR mHealth and uHealth. 2016 Apr;4(2):e69.

11. Lewis TL. A systematic self-certification model for mobile medical apps. Journal of medical Internet research. 2013;15(4):e89.

12. Lewis TL, Wyatt JC. mHealth and mobile medical apps: a framework to assess risk and promote safer use. Journal of medical Internet research. 2014 Sep;16(9):e210.

13. Sankaranarayanan R, Ramadas K, Thomas G, Muwonge R, Thara S, Mathew B, Rajan B, Trivandrum Oral Cancer Screening Study Group. Effect of screening on oral cancer mortality in Kerala, India: a cluster-randomised controlled trial. The Lancet. 2005 Jun 10;365(9475):1927-1933.

14. Lupton D. Apps as artefacts: Towards a critical perspective on mobile health and medical apps. Societies. 2014 Oct 29;4(4):606-622.

15. Mosa AS, Yoo I, Sheets L. A systematic review of healthcare applications for smartphones. BMC medical informatics and decision making. 2012 Dec;12(1):67. 
16. Zhu J, Ebert L, Guo D, Yang S, Han Q, Chan SW. Mobile Breast Cancer e-Support Program for Chinese Women With Breast Cancer Undergoing Chemotherapy (Part 1): Qualitative Study of Women's Perceptions. JMIR mHealth and uHealth. 2018 Apr;6(4):e85.
17. Lee HY, Koopmeiners JS, Rhee TG, Raveis VH, Ahluwalia JS. Mobile phone text messaging intervention for cervical cancer screening: changes in knowledge and behavior prepost intervention. Journal of medical Internet research. 2014 Aug;16(8):e196. 